\title{
THEORIZING AND STRATEGIZING WITH MODELS: GENERATIVE MODELS OF BUSINESS MODELS
}

\author{
Christian Seelos
}




\author{
Christian Seelos \\ IESE Business School \\ Av. Pearson, 21; 08034 Barcelona, Spain \\ Tel.: +34936024038 \\ Fax: +34932534343 \\ Email: cseelos@iese.edu \\ www.iese.edu/IPSS
}

\begin{abstract}
The ambiguity around model-based science is witnessed by the proliferation of meanings of the term business model. We argue that a clearer specification of the analytical, theoretical and ontological validity of models is an opportunity to learn about and understand complex organizational phenomena more systematically. We apply this to research on social entrepreneurship and pro-poor business models that has been criticized as being atheoretical and conceptually ambiguous. Business models are presented as narratives that integrate various actors, actions, stories, and outcomes without a clear perspective of why these elements were selected and what we can learn from them. This paper outlines an explicit modeling process as an investigative tool that enables transparent and systematic theorizing of business models. Using an illustrative case study, we develop a generative model that accounts for the social mechanisms that explain how business models achieve multiple strategic objectives and multiple dimensions of economic and social value creation.
\end{abstract}

\title{
Keywords
}

Business model; social mechanisms; generative model; retroduction.

\section{INTRODUCTION}

'Every company has a business model' affirms Chesbrough (2007: 1) and Magretta (2002: 87) states that 'a good business model remains essential to every successful organization'. The term business model was popularized to characterize e-businesses driven by the emerging internet boom in the 1990s (Applegate, 2001; Mahadevan, 2000). Since then, various authors have positioned the term business model as a key 
concept in understanding organizations but at the same time have voiced concerns that the rapid proliferation of the concept has created an abundance of meanings (Hedman and Kalling, 2003; Shafer, Smith, Linder, 2005; Schweizer, 2005). Ghaziani and Ventresca (2001) employed frame analysis of more than 500 journal abstracts containing the term business model over a period of 25 years and coded the data into 11 different frames indicative of the plurality of meanings and uses of the term. Porter (2001) criticized the conceptual ambiguity of the term as constituting 'an invitation for faulty thinking and self-delusion' (Porter, 2001: 77). Chesbrough and Rosenbloom (2002: 553) point out that the concept 'draws from and integrates a variety of academic and functional disciplines, gaining prominence in none'. It appears that uses of the term business model suffer from either not being explicit what the term tries to explain or trying to explain too much and thus stretching analytical adequacy and practical usefulness.

As in the 1990s with e-businesses, scholars have identified a new outlet for the term business models the 2000s that appears to increase rather than remove ambiguity. The concept of business models is now applied to the particular context of deep poverty, i.e. geographies where the majority of people live in a state of serious deprivation. This context is challenging from both theoretical and empirical perspectives given the variety of local institutional constellations that are very different from competitive markets and mainstream organizational theory (Khanna and Palepu, 1997; North, 1994). Understanding business models in that context requires explorative approaches able to deal with rich contextual data. Poverty continues to be a burning problem and systematic learning from entrepreneurs that develop pro-poor businesses may contribute to social and economic progress. We argue in this paper that conceptual ambiguity around the term business models stifles progress by failing to provide truthful and therefore practical explanations of how these business models work. This understanding is a prerequisite for making better decisions for example around the potential of the focal organizations for scaling up to serve more poor people or for replicating these models in different geographical contexts. The central purpose of this paper is thus to develop a transparent and systematic process that validates the term model in business models that enables a systematic and analytically as well as practically useful understanding of their workings.

\section{Business Models and Poverty}

Recent strategic management and entrepreneurship literatures have framed deep poverty as a trillion dollar opportunity for new business models (Prahalad, 2005). Scholars proposed that new business models can alleviate the stubborn global phenomenon of poverty and at the same time generate real economic returns for companies (Chesbrough et al., 2006; Hart, 2007; Prahalad, 2005). In a recent effort to answer the question how to reach the people at the bottom of the (income) pyramid 
(BoP) successfully, Hart (2007: 142) claims: 'It's the Business Model, Stupid'. Authors have criticized this perspective for simplifying complex social and economic phenomena and not being sufficiently grounded in theory (Jaiswal, 2008; Karnani, 2007; Walsh, Kress and Beyerchen, 2005; Seelos and Mair, 2007). The concept of business models at the BoP is often constituted by narrative accounts of unusual activities, actors, stories, motivations, intentions, decisions, and other elements. The absence of a clear theoretical perspective prompted Walsh et al. (2005) to label Prahalad's (2005) book motivational. Walsh et al. (2005) argue that this literature leaves it unclear how business models actually create value in the sense of eliminating poverty and what the overall contribution of these models is.

A related stream of literature on the topic of social entrepreneurship (Certo and Miller, 2008; Seelos and Mair, 2005) has also drawn attention to new business models able to serve the poor. Like the BoP literature, there has been little progress in developing a shared understanding of the phenomenon or a formal treatment of the concept of social entrepreneurship business models and how that concept facilitates more systematic theorizing (Short, Moss and Lumpkin, 2009). This creates a dilemma for several audiences. For companies, the lack of systematic learning from business models does not facilitate strategic decision making. Given its potential, but also its unusual nature and resulting higher risk involved in enacting the opportunity space at the BoP, more strategic insights are urgently required. Policy makers, philanthropists, and foundations interested in innovative approaches to poverty elimination need to better understand how to allocate resources to those organizations that create value efficiently and more productively. Academics require better analytical tools that capture the complexity of these business models in their particular context. Explanation of what works and what does not is facilitated by the development of models that explain how mechanisms contingently generate organizational outcomes. Several authors have called for more idiographic comparative research to unearth a richer set of mechanisms as a basis for a better theoretical foundation of organizational phenomena (Tsoukas, 1989; Sayer, 1992).

To advance efforts towards these goals, this paper develops a perspective of business models grounded in model theory that argues for their roles as autonomous instruments of investigation (Morgan and Morrisson, 1999, McKelvey, 2002). Model development follows a proposed realist turn in management science that calls for an analytical commitment to richer ontologies (Reed, 2005). Realism employs generative models, i.e. models that explain how social mechanisms contingently create observable outcomes, as central analytical devices (Pawson, 1989; Bunge, 2004; Demetriou, 2009). This paper contributes to the literature on business models a practical and transparent approach to 
modeling that aims to overcome some of the following shortcomings of the existing BoP and social entrepreneurship as well as the more general strategy literatures:

1. The focal pro-poor organizations usually have multiple social and economic objectives that are challenging to reconcile from a strategy perspective where traditionally financial performance measures are the core explananda as is the often the case with traditional concepts of business models (Ray, Barney and Muhanna, 2003; Schweizer, 2005);

2. Pro-poor business models often span organizational boundaries and integrate resources from organizations and actors with very different cultures and objectives, e.g. models across for-profit companies and not-for-profit NGOs (Seelos and Mair, 2007);

3. How resources get configured into business models to constitute organizational mechanisms that generate value remains a "black box" in the strategy literature (Priem and Butler, 2001; Sirmon, Hitt and Ireland, 2007). Because bad choices about resource allocations are particularly painful in a context of low munificence such as for deep poverty (Sirmon et al., 2007) progress in understanding how resources enable or constitute mechanisms that create benefits is much needed.

The paper proceeds as follows: We will first reflect on the role of models in science and the benefits of model-building in support of social science practice. We then draw on the literature on theoretical models to specify what the requirements are that define useful and valid models. This generic model will then be applied to an illustrative case study to demonstrate the process of how to build a generative model of a business model, i.e. an account of how social mechanisms contingently generate organizational outcomes. Finally, we discuss why this conceptualization of business models is useful from theoretical and practical perspectives.

\section{THE ROLE OF MODELS IN SCIENCE}

Models are central to contemporary practice of science. Frederick Suppe (2000: S109) reflecting on 30 years of theory development following the demise of the received view of theories by Carl Hempel in 1969 concludes: 'Today, models are the main vehicle of scientific knowledge'. Philosophers of science have highlighted the limits that the complexity of the universe poses for our scientific objective of exploring how the world works. Models have been advanced as an important means to overcome this limitation. Giere (1999: 77) states that 'some ways of constructing models of the world do provide resources for capturing some aspects of the world more than others'. He sees models as central tools in the sciences for explicitly representing selected aspects of the world for various purposes of scientific investigation (Giere, 2006). Models may represent empirical or theoretical content. Empirical scale models, for example, are often mirror images of real or imagined objects such as an architect's model of a proposed building 
to facilitate constructing decisions (Frigg and Hartmann, 2009). Maps are empirical models of real objects such as streets, buildings, rivers in a configuration that facilitates particular uses (Azevedo, 1997). Empirical models can also be formal models of data (Suppes, 1962) that are used abundantly for example in the form of graphs.

Models representing theory have been associated with the semantic view of science (Suppe, 1989; Suppes, 2002). Models thus are satisfactory realizations of all sentences of a theory. They are sets of objects that resemble and provide meaning to a set of postulates, theorems or axioms (Downes, 1992). Models of theories can also be concrete objects. Examples are models of the planetary system or a pendulum that result from engaging Newtonian Mechanics as a modeling framework (Hartmann, 2008). The pendulum as model satisfies and provides meaning to the equations of classical mechanics. It also demonstrates the role of models as tools for both theory testing and theory creation. For example Foucault used the pendulum to create a new proof for the earth's rotation.

But beyond what Van Fraassen (1980) called the foundational work of a semantic account of the structures and content of theories, philosophers of science have emphasized the central role of model building as actual scientific practice. Both in the natural (Downes, 1992; Godfrey-Smith, 2006) and in the social sciences (Merton, 1968; Bourgeouis III, 1979) scholars have proposed a shift from grand theories to the actual process of theorizing as a middle way between fully developed theories and any kind of concept or working hypothesis guiding investigation. Model-based science enables a shift from theories to theorizing (Morgan and Morrisson, 1999). A practical advantage of models as idealized representations is to reduce the complexity of target phenomena that would otherwise prevent or make any systematic inquiry into selected aspects impractical (Frigg and Hartmann 2009; Giere, 1999). Hartmann (2008: 98) reflecting on the practical advantages of models over theories states: 'They are also more intuitive, visualizable, and ideally capture the essence of phenomena in a few assumptions'.

However, model-based theorizing suffers from a proliferation of model types and an ambiguity of the meaning of the term model (Frigg and Hartmann, 2009; Godfrey-Smith, 2006). And this is also reflected in the proliferation of meanings around the term business model. Therefore, a main objective of this paper is a clear and transparent specification of model-based theorizing that transforms the term business model into a valid concept for model-centered scholarly investigation.

\section{SPECIFYING MODELS IN THE SOCIAL SCIENCES}

Several authors point out the important role of models in the social sciences linking theory and the observable world (Giere 1999; McKelvey, 2000; Franck, 2002; Brante, 
2010). McKelvey (2000: 773) goes so far as to state that 'in order for organization "science" to avoid or recover from scientific discredit, and institutional illegitimacy it must become model-centered". Because models selectively represent theoretical and empirical elements, researchers must explicitly specify the relationships of theory/model and model/world as an integral part of the model-building process. We integrate the perspectives articulated by Azevedo (1997), Morgan and Morrison (1999), and McKelvey (2002) and postulate that model validity requires theoretical, ontological and analytical adequacy.

\section{Analytical Adequacy}

Models in the social sciences are necessarily idealizations and therefore no single correct model can exist. Rather, models are more or less useful given the particular interest of the researcher (Azevedo 1997). In the words of Mäki (2010: 179): 'Models are created by modellers to serve their interests in certain situations. The modellers goals and contexts provide the pragmatic constraints on modeling'.

The research objective and the concrete research question thus determine the content and form of models and whether they are primarily derived from theory or empirical data. Extensive research designs may be based on formal models constituted by hypotheses deduced from theory for the purpose of statistical testing (Sayer, 1992). Intensive designs may build models that are generated by inductive, abductive or retroductive logics to infer rich but more idiosyncratic causal explanations (Tsoukas, 1989; Demetriou, 2009) This has implications for what theories are adequately engaged to inform model creation and also what empirical content to look for and integrate into the model. Being explicit and systematic about the set of analytical model choices is thus a crucial feature of rigorous and transparent scientific methodology. Analytical adequacy in the social sciences is evaluated by the ability of the model to adequately describe, explain, and predict social phenomena given the particular interest of the investigator.

\section{Theoretical Adequacy - The Theory/Model Relationship}

Theoretical adequacy focuses on the link between theory and the model, and specifies which theoretical elements are formalized into the model. Theory as used here does not explain real-world behavior but model behavior and theory is thus a toolbox for the construction of models (Suarez and Cartwright, 2008). The idea is to achieve what Azevedo (1997) calls focused simplification. I interpret this concept as the ability of the modeler to specify a transparent and consistent process of idealization and thus the constitutive elements and the particular form of the model. Focused choices about what theory to engage and how also specifies which types of empirical elements are significant. Brante (2010) illustrates this with the example of Perrow's four interest 
theories concerning power in organizations. Because theory choice follows interest choice the four theories support the creation of four different idealized and thus simplified models: the elite model, the pluralist model, the ethnomethodological model or the necessity model. The type of theory engaged thus defines the scope for the collection of specific organizational data that go into the model. This example illustrates the dependencies between analytical, theoretical, and ontological adequacy for model creation and model-based theorizing. We evaluate theoretical adequacy against the ability of selected theories to specify model structure, content, and behavior that strengthen the explanatory power of a model according to the researcher's interest.

\section{Ontological Adequacy - The Model/World Relationship}

Ontological adequacy reflects how well the selected parts of the model resemble aspects of target phenomena. McKelvey (2000) states that different sub-structures of the model need to represent specific counterparts in the real world. If non-linearities such as feedback cycles define sub-structure interactions, then composite or emergent outcomes also need to be considered (Sawyer, 2004). Ontological adequacy thus ensures resemblance between models and the world and this feature contributes to the validity of models as independent tools for theorizing (Morgan and Morrison, 1999). A transparent and systematic model/world relationship enables to investigate the model in place of its target 'without sacrificing the quest for knowledge about real systems'. (Mäki, 2010: 179).

An important consideration is also the particular ontological commitment of the researcher. Scholars have called for making this commitment more explicit. Whether a researcher operates from a commitment to objectivist or subjectivist ontologies is likely to influence modeling choices (Johnson and Duberley, 2000). For example, whether social mechanisms are conceptualized as empirical variables that fill in the black boxes between dependent and independent variables, theoretical constructs as part of midlevel theories or real observable or unobservable processes determines model properties in important ways (Mahoney, 2001; Demetriou, 2009).

Because of the many choices involved in model building, transparency and a systematic account of the modeling process is key. The links and interdependencies of analytical, theoretical and empirical perspectives generates an iterative, progressive process of model building constrained by a continuous evaluation of all three aspects of model adequacy.

\section{A GENERATIVE MODEL OF A BUSINESS MODEL FOR CAUSAL EXPLANATION}

To illustrate this set of analytical, theoretical and ontological choices we model the business model of Aravind in India, a large-scale organization that has grown its ability 
to provide health services to the poor for more than 20 years. We first present a brief overview of Aravind and then detail the steps of developing the model.

\section{Focal Organization: Aravind ${ }^{1}$}

Aravind in India is the largest group of eye hospitals in the world. Their mission is to eradicate unnecessary blindness, and they have pioneered a novel approach to delivering eye surgery for cataracts that integrates free surgery for the poor as a major strategic objective. Cataracts affect millions of people all over the world and are routinely treated in wealthy countries by replacing the clouded natural lens of the eye with an artificial lens to restore sight. However, market prices of lenses and surgery have traditionally been out of the reach of most poor people. Partial or full blindness limits or prevents the ability of the poor to engage in economic activity. In addition to the personal hardships of the blind in poor countries, limited social welfare and insurance systems or private savings put a severe burden on the supporting families and this causes significant economic losses and social and individual suffering. According to the World Health Organization, the economic costs of blindness are estimated at US $\$ 25$ billion. Access to quality eye care and appropriate technologies would make up to $80 \%$ of blindness preventable or curable (World Health Organization, 1997; World Health Organization, 1999).

In 1976, Dr. Govindappa Venkataswamy a retired ophthalmologist founded Aravind in the city of Madurai in the Indian state of Tamil Nadu. Over the years Aravind has expanded to a group of five hospitals that currently perform over 280,000 eye surgeries annually and provide eye care services to more than 2 million outpatients. While more than half of their high-quality eye surgeries are provided to the poorest for free, Aravind manages to generate significant operating profits (see Figure 1a). Profits are used to invest in capacity building and increasing the scope and scale of Aravind's activities ${ }^{2}$. Figure $2 \mathrm{~b}$ shows the growth in patient numbers over time indicating a robust ability of its business model to achieve organizational goals.

\footnotetext{
${ }^{1}$ Based on our own research as well as publications by Brilliant and Brilliant, 2007; Rangan and Thulasiraj, 2007; Tabin, 2007.

${ }^{2}$ Data provided by R. D. Thulasiraj, Executive Director of the Lions Aravind Institute of Community Opthalmology.
} 
Figure 1a. Revenues and expenses of Aravind between 1980 and 2005 and percentage of free versus paying patients treated in 2005.

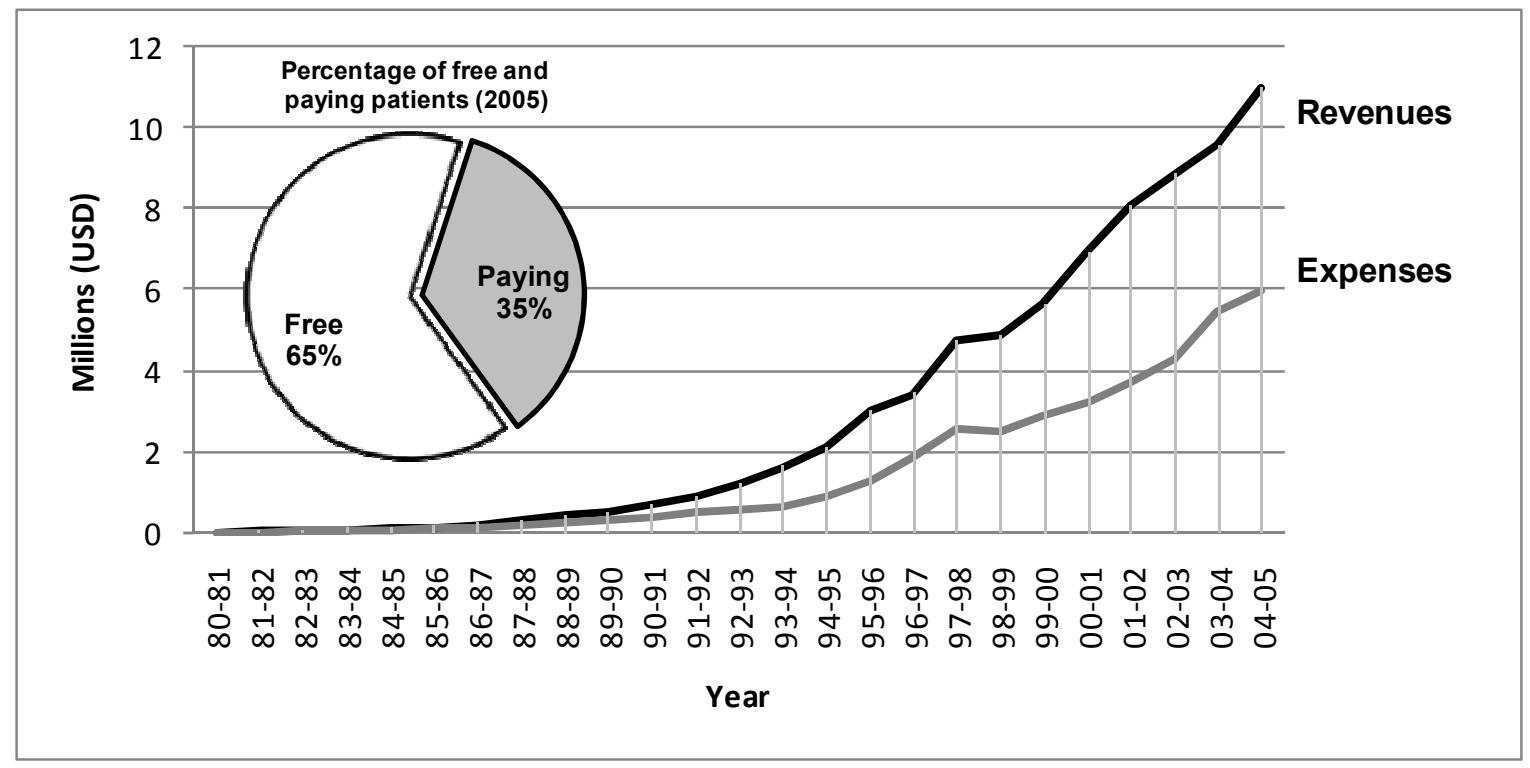

Figure $1 \mathrm{~b}$. Numbers of patients who received eye operations between 1980 and 2005.

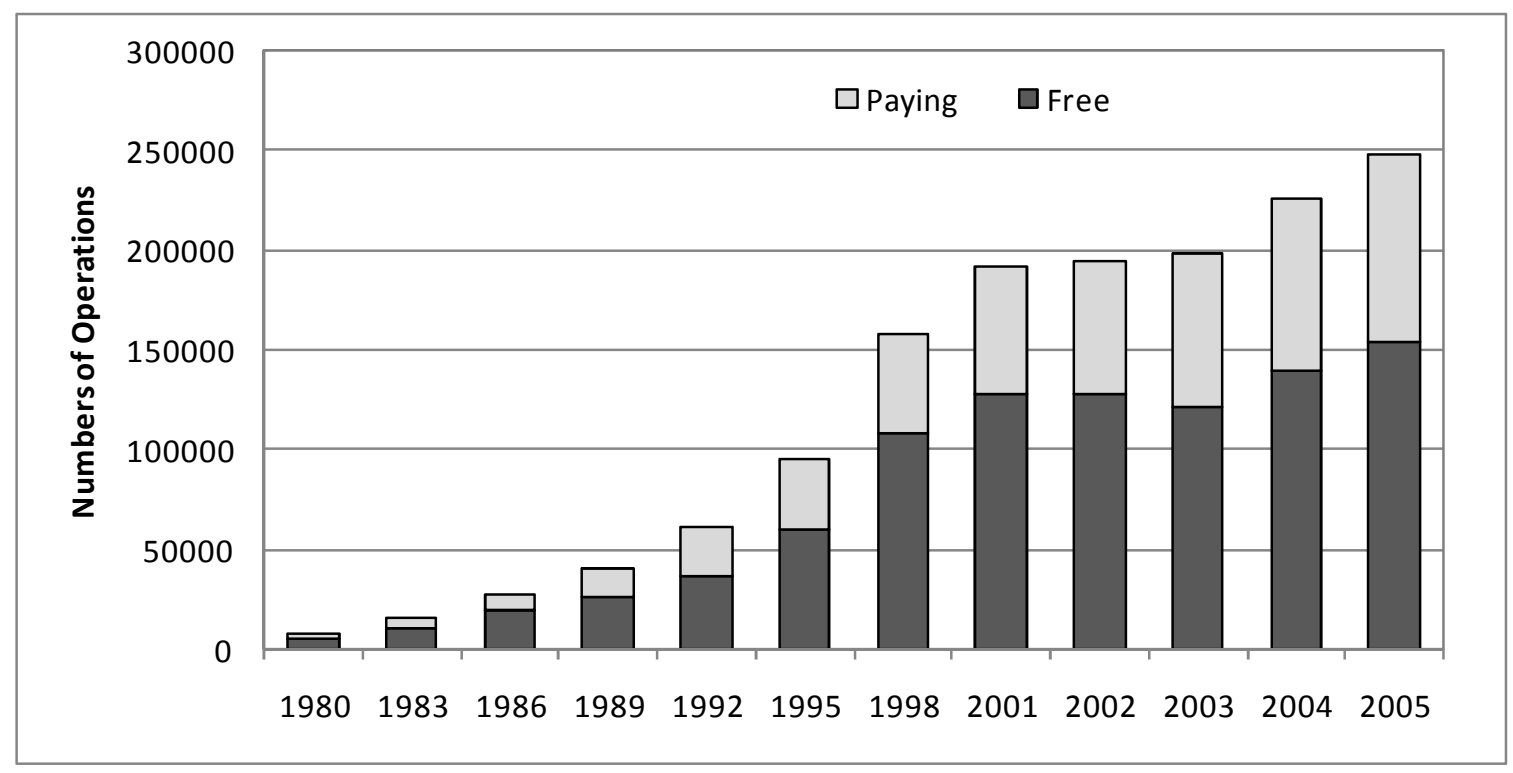

In 1992, David Green, a US based entrepreneur started the manufacturing company Aurolab in order to remove an important bottleneck in Aravind's model - the availability of high-quality lenses required for surgeries. When Aurolab started, the industry was concentrated in and dominated by a few players. Low price sensitivity of wealthy 
customers and insurance systems that were obscuring the real prices from patients allowed the manufacturers to enjoy large margins. These features of their competitive context partly explain why manufacturers did not consider India a significant market in the early 1990s. Aravind's business model was constrained by the willingness of manufacturers to donate lenses. With the help of IOL International, a US manufacturer that needed additional manufacturing capacity, Green built Aurolab as a state-of-the-art production facility next door to Aravind and integrated it with the patient care model of the hospital. The technology transfer from IOL was compensated in the form of lenses produced by Aurolab. The new low-cost and high-quality lenses provided by Aurolab were a crucial element in enabling the significant expansion of the model after 1992, as seen in Figure 1.

\section{Preparing a model template for Aravind}

\section{Analytical Perspective: Objectives and Research Question}

We used model building as an analytical strategy to systematically understand the potential of Aravind to achieve its recently formulated ambitious growth objectives. The growth objective reflects the sad reality that demand for eye surgeries in India remains large and competition over providing health services that also serve the poor remains low. Therefore, treating more people for Aravind implies building higher capacity or higher productivity or both into its business model. Based on our research objective we decided to develop a generative model of Aravind's business model. Generative models account for the key social mechanisms that explain how Aravind does what it does and this has implications for the ways in which Aravind is able to change as an organization (Pawson, 1989; Bunge, 2006).

Aravind operates in the context of deep poverty in India, and acquiring the necessary resources to operate an efficient health service model is a key constraint. A main research question that guides selection of the theoretical and empirical perspectives for constructing the generative model of Aravind is thus: What is the role of resources in Aravind's business model in explaining how it achieves its strategic objectives and how does the current configuration of resources enable or challenge further organizational growth? This question is relevant given our analytical objectives because achieving growth requires an understanding of how Aravind's business model works and its potential and limits for acquiring and productively configuring additional resources in its current or other geographical contexts. An appropriate theoretical perspective for our modeling purpose that is expected to illuminate our research question is the resourcebased view of the firm.

Theoretical Perspective: Theory/Model Relationship 
The resource-based view (RBV) of the firm has become a dominant perspective in the field of strategy. Early pioneers of this perspective have framed organizations as a collection of productive resources and the services they provide (Penrose, 1959), or a collection of activities because 'an activity consists of a combination of resources in some manner' (Rubin, 1973: 939). Several researchers further developed this view of strategy based on the resource perspective of the firm to explain performance differences between organizations competing in similar strategic external environments (Barney, Wright and Ketchen, 2001; Lockett, O'Shea and Wright, 2008).

Which elements of the RBV should go into the model? Boumans (1999) compared model building to baking a cake without a detailed recipe. The message is that we need not start blank but can build on knowing important elements and ingredients that go into the model. Thus for our perspective on modeling, the purpose of engaging existing theory is not to test hypotheses but to inform model content and behavior.

Sirmon et al. (2007) proposed a theoretical framework of the RBV that focuses on the internal resource management of organizations and attempts to shine some light on the black box of resource configurations. The authors propose three distinct dimensions: structuring, bundling and leveraging resources. We use these dimensions as the main conceptual framework to develop a model of the business model of our focal organization Aravind. Structuring, bundling and leveraging resources thus inform the content and behavior of our model. The three perspectives also enable us to link theoretical elements more explicitly with concrete parts of Aravind in its particular environment show in the next section.

The first dimension of this RBV framework is structuring the resource portfolio. The resources that enable operating an eye hospital are easy to observe and do not pose much analytical ambiguity. However, accessing these resources is a challenge in environments of low munificence - a defining characteristic of the context of deep poverty. Resources are scarce and thus often employed in some alternative use. Resource exchanges are inefficient, and economic valuation of resources is difficult to impossible. Structuring the resource portfolio thus is expected to require partnering with various organizations to access specific types of resources. However, limits to partnership strategies also imply that internal development and accumulation of resources is expected to be a core set of strategic organizational activities. We therefore separate this RBV dimension into two distinct dimensions: accessing and accumulating resources.

A second RBV dimension is bundling of resources to create value. We simplify the various bundling processes outlined by Sirmon et al. (2007) into the construct of 
resource configuration. This refers to integrated sets of resources that generate the essential organizational activities as part of the value-creation logic of an organization.

The third RBV dimension proposed by Sirmon et al. (2007), leveraging resource bundles to achieve competitive advantage also needed to be adapted to our purposes. The context of deep poverty is not comparable to a competitive market where relative performance is traditionally measured in comparative financial metrics. Furthermore, needs are not coupled to a willingness to pay (WTP) for most poor people due to institutional factors (e.g. appropriateness to get eye surgery for certain class members), cognitive factors (not being aware of the need for eye surgery despite progressive loss of vision) or economic factors (services are not within the reach of the poor). We thus adapt the dimension of leveraging resources by specifying the consequences of deploying resource bundles to explain how they achieve the core financial and nonfinancial strategic objectives of an organization.

\section{Ontological Perspective: Model/Organization Relationship}

A main challenge of conceptualizing business models in the context of deep poverty is the sheer complexity generated by the numbers of unusual actors and organizations, social and economic resources and objectives and by environments characterized by institutional immaturity. An infinite number of organizational resources and activities could be integrated. Many of these would be expected as neither necessary nor sufficient to explain the phenomenon of interest. Understanding which ones matter requires what Weick (1989) refers to as an emptying operation that strips away idiosyncrasies that do not have explanatory power. Parsimony enables us to see the particular elements that are often hidden amongst the incidental and idiosyncratic. Weick (1989) suggests an evolutionary process of trial and error: thought experiments that involve variation, selection and retention to come up with a model that best makes sense of a phenomenon. However, he leaves it unclear how researchers could do this in a systematic and transparent manner. Simplifying properties of complex social phenomena into more general principles requires a transparent process that is sufficiently formalized to enable interpretation of the findings by others (McKelvey, 2002).

Our approach to generative models helps to meet this challenge. First, we engage an explicit theoretical framework - the RBV - to specify the types of empirical data expected to inform our analysis. Second, we explicitly embrace an ontological commitment grounded in scientific realism. From this perspective, social explanation is to exhibit or assume the sets of mechanisms that make a social system work the way it does. Bunge (1997, 2004, 2006) developed strong arguments for a limited set of explanatory specifications that enables modeling any bounded system. He defines the minimal 
required set of specifications for a social system such as an organization as: constituents, structure, mechanisms and environments. We apply this set of four system variables to our modeling approach by making the following adjustments:

1. We integrate constituents in the form of social actors as the principal causal agents in our analysis. We also integrate other material and immaterial objects to the extent that they enable or constrain achievement of organizational objectives.

2. Structure, following Tsoukas (1989), refers to the set of relations between actors that have both enabling and constraining effects on the generation of mechanisms and outcomes.

3. Mechanisms refer to the set of distinct processes that make a system 'what it is and the peculiar ways it changes' (Bunge 2006, p.126).

4. We treat environment as referring to the constituents, structures and mechanisms in the task environment of the focal organization that influence the outcomes an organization can achieve.

We believe that this modeling specification is relevant given our research objective. As Pickel (2007: 402) states: 'Any model leaving out one or more of these elements is likely to lead to misinterpretations of what is actually going on that may subsequently give rise to faulty social technologies (e.g., ill-conceived economic policies, management fads, counterproductive labor-saving initiatives, or costly mergers)'.

We propose that generative models are ontologically constituted by the constellations of actors, relationships and mechanisms that comprise a social phenomenon. The model explains how this constellation generates empirical outcomes. Because theory is interpreted from contextual empirical "realities" and mechanisms are often not observable but need to be conjectured the model becomes an investigative tool independent of but informed by both theory and data. 
Figure 2. Conceptualization of Business Models as Generative Models

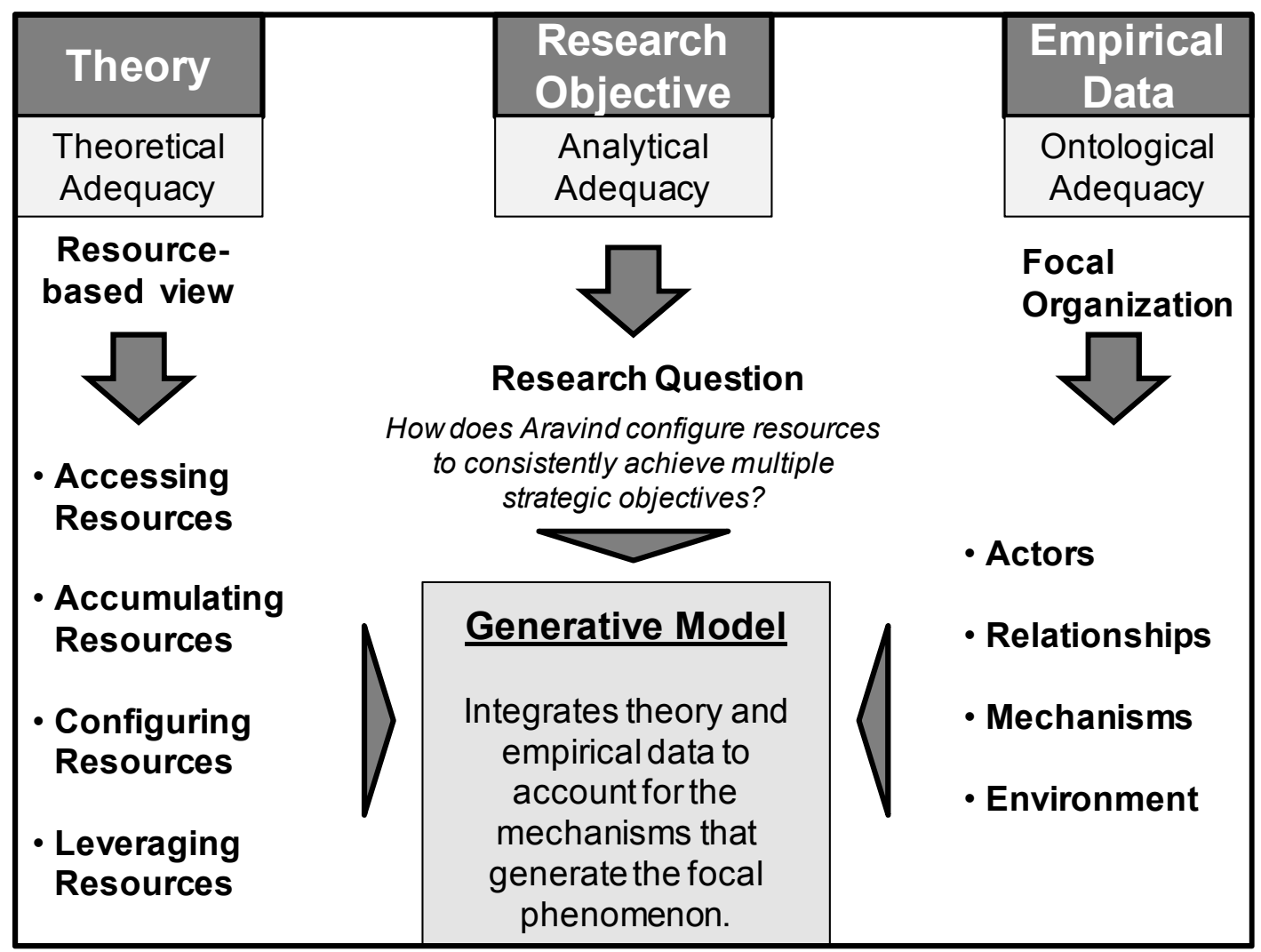

Figure 2 summarizes the relationship of the generative model of Aravind's business model to both theory and empirical data. It captures the important perspective of models as tools and that their analytical validity is defined and constrained by the research question. The research objective thus guides selection of theoretical elements, in this case the RBV, and specific empirical elements, in this case the specified types of data of the focal organization acting in its particular environmental context. Theoretical and ontological adequacy enables an interpretation of the RBV in the form of a link to the empirical reality of the phenomenon investigated. This informs the modeling process: the creation of a generative model that explains how Aravind creates multiple dimensions of value in the context of deep poverty.

\section{Working with the model template}

Realist explanation of organizational phenomena proceeds along a retroductive logic, where outcomes are explained as the consequences generated by social mechanisms. 
Tsoukas (1989: 558) states it like this: 'During the process of explanation, the first stage involves (a) resolving the actions themselves into their constitutive components and (b) theoretically redescribing these components so that their inner constitution is revealed (Bkaskar, 1978)'. This is the approach we follow in building our actual model. First we use the RBV template to map the relevant constitutive actors, structures and mechanisms and then - in a second step - we provide the final model constituted by the set of observable and conjectured mechanisms that generate empirical outcomes.

Figure 1a provides empirical evidence that Aravind generates significant profit margins despite a majority of free operations that create costs and no income. Furthermore, one of Aravind's main strategic objectives is to provide the same high-quality surgeries for paying and free patients which also increases costs to its operation. This constellation of organizational objectives appears counterintuitive. The very successful achievement of all these objectives concomitantly thus requires explanation. To build a model that formalizes the core mechanisms that generate this outcome, we have captured the critical empirical elements of Aravind's business model using the RBV template. This followed a process of independent coding by two researchers from a number of available information sources captured during several field trips to Aravind and a number of interviews with Aravind personnel and stakeholders. Figures $3 a$ and $3 \mathrm{~b}$ list those elements in the RBV categories, defined in figure 2, that explain how resources are accessed, accumulated and configured and finally leveraged to achieve the four core strategic objectives of Aravind. The elements of figure 3 constitute the content of a generative model but are only a first step in specifying model behavior. It does not yet provide a plausible explanation how organizational outcomes are generated by the particular constellation of actors, relations and mechanisms that are constitutive of Aravind and its task environment. 
Figure 3a. Core elements of Aravind's business model selected for integration into the generative model - Accessing and accumulating resources

\begin{tabular}{|c|}
\hline Accessing Resources \\
\hline $\begin{array}{l}\text { - Aravind family members as eye doctors and senior management provide leadership, medical services, expertise and maintain a } \\
\text { - Local and international eye doctors are attracted by Aravind as a premiere training institution with large numbers of „interesting“ } \\
\text { cases due to the high volumes and the strong sense of mission. } \\
\text { - NGOs and foundations (e.g. Seva, Rotary, Lions Clubs) provide funds for new projects, expertise and know how because of } \\
\text { Aravind's mission to prioritize health services for the poor. } \\
\text { - The caring mission of Aravind overcomes hesitation by families to let their daughters leave home and become nurses. } \\
\text { - Partnerships with leading international ophthalmology research centers facilitates knowledge sharing and access to best practices. } \\
\text { - Community partners in rural villages provide publicity, marketing and demand generation using local funds and services and their } \\
\text { - Aurolab partners with IOL International, a US lens manufacturer to transfer key technology to India. }\end{array}$ \\
\hline $\begin{array}{ll}\text { Accumulating Resources } \\
\end{array}$ \\
\hline $\begin{array}{l}\text { - Active nurturing by Aravind's leadership team of the strong sense of mission and purpose, values and dedication by all staff builds } \\
\text { - Nurses culture of excellence and service. } \\
\text { identify with Aravind values and become outstanding paramedics. } \\
\text { - Exchange programs with top institutes prevent fears of de-skilling amongst Aravind doctors due to their repetitive tasks of high- } \\
\text { volume cataract surgery; as a result, experienced highly productive doctors remain at Aravind rather than leaving for jobs with } \\
\text { - } \text { - Araviner task variety. } \\
\text { pool of existing staff and builds additional eye doctors and nurses as a basis for capacity expansion. } \\
\text { - Internal research and division pushes for innovation and improvement in all areas of Aravind's value chain. } \\
\text { - Internal consulting division implements constant process improvements, monitors quality, benchmarks and diffuses best practices. } \\
\text { - Aravind training institute requires constant reflection on metrics, best practices and problem solving mechanisms - nurtures a } \\
\text { performance culture and ensures fast diffusion of innovations and improvements across units and hospitals } \\
\text { - Aurolab was established to control the provision of high volumes of quality eye lenses at extremely low price points. } \\
\text { - Steep learning curves through focused job designs (doctors do only essential parts of the surgical procedures) and high volumes. } \\
\text { - Designs for "appropriate facilities" - only bare functionality to maintain patient dignity and surgical quality for free surgeries and } \\
\text { more comfortable facilities for paying patients; facilitates self-selection because paying patients value the additional comfort. } \\
\text { Many programs with NGOs, foundations and R\&D centers build partnership competencies and flexible use of scarce resources } \\
\text { such as doctors and hospital space. }\end{array}$ \\
\hline
\end{tabular}

Figure 3b. Core elements of Aravind's business model selected for integration into the generative model - Configuring and leveraging resources to achieve strategic objectives.

\footnotetext{
Configuring Resources
- Aravind family constantly engages with doctors and nurses to prevent mission drift and non-productive activities; constitutes a mechanism to solve problems fast and ensure consistent decision making processes.

- Nurses, doctors and infrastructure are organized into a formalized workflow for optimized efficiency of surgeries, patient-care and administrative tasks - constant displays of metrics ensure evidence-based decisions and identification of improvement areas.

- Community resources are integrated with hospitals to decentralize services into rural areas; eye camps enable rapid screening and only groups of selected patients are brought by busses to hospitals; manage pace of community involvement to fit capacity.

- Busloads of patiens from villages arrive at Aravind $\rightarrow$ stretches capacity and requires constant optimization of workflows across all hospital areas otherwise the business model would break down in short time (mistakes, stress, frustration, unhappy patients etc.)

- IT-enabled vision centers link Aravind doctors as bottleneck resources with rural needs to maximize use of doctor's time.

- Aurolab employs target costing to manufacture affordable, high quality lenses and expands to international markets and leverages competencies to grow into other product categories.

- Aurolab and Aravind are operated as separate organizations at arms-length with distinct cultures, structures and processes to force Aurolab to remain competitive and contribute to profit margins.
}

Leveraging Resources

- Outstanding reputation for high quality surgeries

- Reputation as an extremely caring organization

- Very high productivity levels (e.g. surgeries per doctor)

- Low cost operation

- Large volume of patients can be treated

- High-performance culture dedicated to their patients

- Continuity and resilience of its business model

- Capacity for expansion

- Long-term strategic relationships and global ambassadors

- Competitive organization despite lack of competition
Strategic Objectives

- Large Scale (treat as many people as possible)

- High-Quality Surgeries (don't let poverty compromise service quality)

- 60/40 Ratio of Free to Paid Surgeries (don't deny the poor access to treatment)

- Profits (generate earned income to remain independent and enable further expansion) 


\section{Building the generative model}

This part of the model building process requires and encourages reflection on the question: what does mechanism-based explanation mean in practice? Many generative mechanisms cannot be discovered as ontologies following an inductive logic because they are unobservable (Demetriou. 2009). Social phenomena are generated by unique sets of mechanisms operating in parallel. They may cancel or reinforce each other and thus the concrete outcomes of sets of social mechanisms in action cannot be deduced from theory (Sayer, 1992). Rather, mechanisms are conjectured into the model through a retroductive logic.

To implement this analytical strategy, we start the modeling process by mapping Aravind's core strategic objectives (Fig 3b). The actual achievement of the core strategic objectives constitutes what Bunge $(2004 ; 2006)$ defines as the essential mechanisms of an organization, i.e. those things that only it and its kind can do. This model specification has the advantage that modeling remains grounded in a set of observable key mechanisms for which we have good empirical evidence over time. Practically speaking, we put the four strategic objectives on a blank piece of paper. We then work backwards by integrating the main information provided by our analysis of resources in figure 3 . This can be done by using sticky notes that can easily be shuffled around to capture emerging ideas about model configurations. The focus is on providing explanations how and why individual strategic objectives are achieved and reflection on the links to and consequences this might have for other objectives.

The modeling process creates novelty beyond the theoretical or empirical perspectives engaged. Retroduction follows a similar logic than abduction that Peirce (1982) sees as a way to discover new ideas given surprising phenomena. Building the generative model requires thought trials or conjectures that link the elements of Figure 3 into a holistic model. If the model were true, it would explain how various resources are configured and leveraged to achieve outcomes. This requires connecting the elements that are given in a more linear manner in the RBV template in figure 3 into multiple cause/effect relationships, i.e. specifying how elements generate or co-generate outcomes. In practice this works by formalizing thought trials and conjectures by arrows that link the elements we have earlier put on sticky notes. Arrows constitute causal explanations that specify mechanisms understood as the set of real processes and events that generate specific outcomes. For example, the large numbers of surgeries provided and the focus of doctors on only the essential tasks of surgery constitute a constellation of mechanisms that generate intense task repetition and thus a steep learning curve for Aravind doctors. As a result, Aravind accumulates a pool of the best eye surgeons in 
India. This also creates a reputation for high quality surgery. The additional scale provided by treating large numbers of poor patients thus contributes positively to overall quality and it also generates a reputation of being a caring organization. This constellation then provides a plausible explanation why patients who are not poor are willing to pay. We thus formalized this set of mechanisms into our generative model in Figure 4.

Figure 4. The generative model of Aravind maps the configuration of relationships of actors (shaded rectangulars) within Aravind and its task environment and the mechanisms that plausibly explain how main strategic objectives (oval boxes) are achieved.

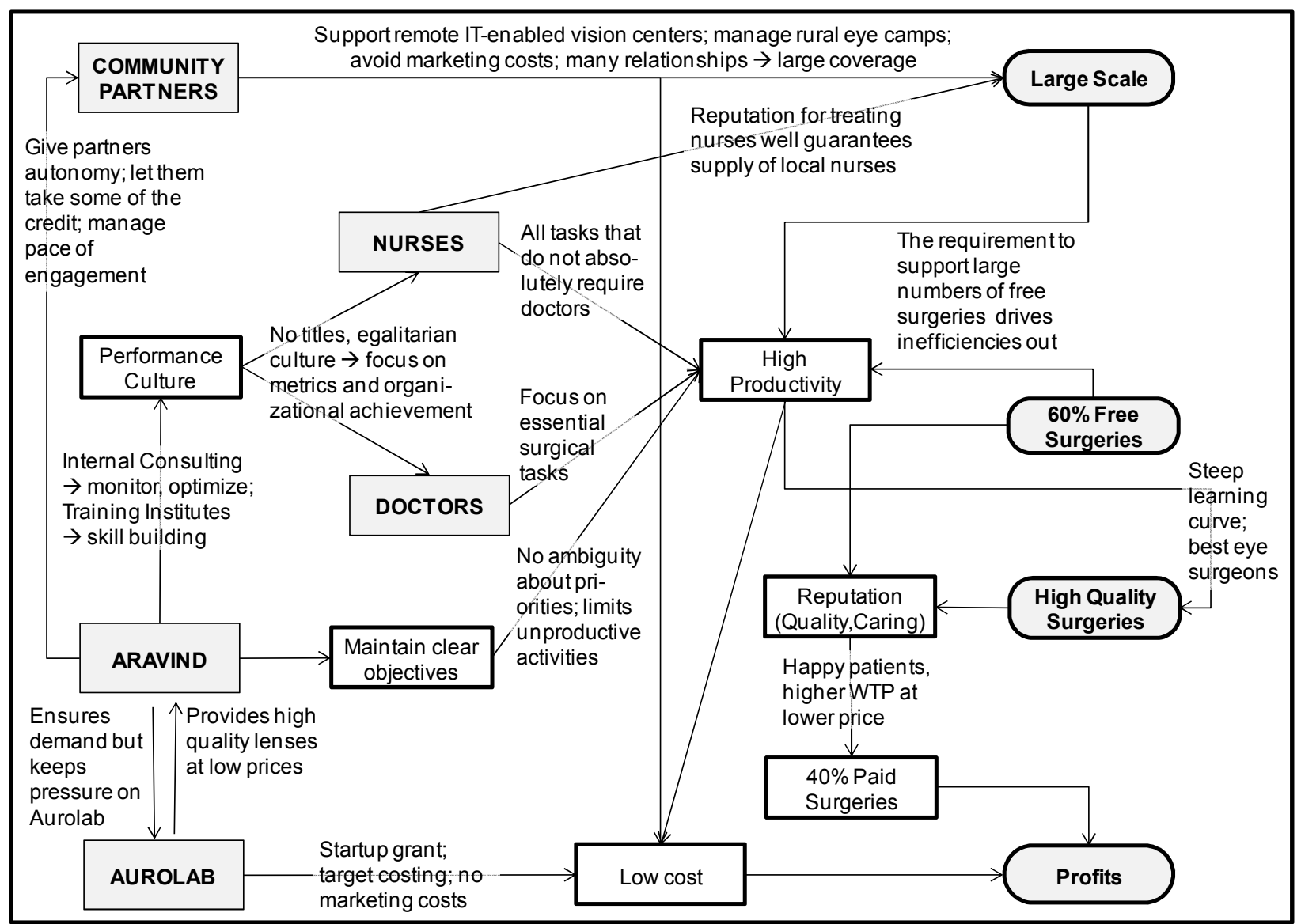

Model building is iterative and constrained by the specified theoretical and empirical perspectives. The challenge for the modeler is to come up with a set of plausible hypotheses or propositions that constitute explanatory links between the substructures of the model and the strategic objectives of the modeled organization. Weick (1989) argues that plausibility is a substitute for validity and, by reflecting on whatever data are available to select and retain conjectures, the model develops and progresses through 
testing for empirical adequacy as much as can be done given available data. Figure 4 represents one possible outcome of this process; a generative model of Aravind that adequately satisfies our research focus and adequately engages a theoretical basis and available data.

\section{Elaborating the generative model}

Demetriou (2009) highlights the need to support generative models by narratives that fill in the blanks, provide context and anecdotal evidence that makes the model richer and strengthens its plausibility. Some mechanisms can be more directly substantiated from available data. For example, several Aravind managers have highlighted the important connection between the need to integrate high volumes of non-paying patients and radical elimination of inefficiencies as a crucial factor to success in this model. The objective of providing free surgery also helps to access community partners as a valuable "low cost" resource. Free operations are made very cost-efficient because many patient-related activities are managed by community partners. Free operations are provided with very basic facilities such as 10-people sleeping rooms with no air condition or private bathrooms. This feature solves the moral hazard problem by a process of social self-selection, creating an effective barrier to those who can afford to pay demanding free treatment: wealthier people in India do not want to sit in the same waiting rooms as the very poor and desire more comfortable or even air-conditioned rooms. Nevertheless, the quality of the surgery is the same for both paying and nonpaying patients by rotating doctors and nurses between facilities.

Free operations build a powerful reputation of being caring and being fair. Anecdotal evidence from several interviews indicates that paying patients value these attributes independent of quality attributes and consider Aravind superior to other hospitals. This explains their WTP for these services: they perceive Aravind as a better deal than other hospitals but are still only required to pay average market prices. This drives the volume of paying patients as evidenced by the growing revenues in Figure 2. Scale, along with a diversity of interesting patient cases, makes Aravind an attractive training center which receives top doctors from all over the world at very low labor costs, and the number of applications for Aravind training centers continues to rise. Several visiting doctors interviewed by the author at Aravind have verified the high quality and productivity of Aravind operations. Aravind reports that their doctors perform about 2000 operations per year, compared to average operations at Indian hospitals of about 250. All the cultural, learning and operational mechanisms that enable this high productivity as shown in Figure 4 are important factors that explain how Aravind is able to keep costs low. Being able to charge market prices combined with a low cost structure and high volumes plausibly explains the profits generated in Aravind's business model. 
High-quality Aurolab lenses achieved certification for sale in the European Union and the United States; a fact which would potentially net much higher market prices. This feature of the business model could be a strong competitive threat to incumbent manufacturers if Aurolab chose to exploit it. At the moment, however, Aurolab is exporting lenses to about 120 countries mainly to serve the needs of NGOs and not-for-profit hospitals. We only have anecdotal data on Aurolab because they do not release financials, but Aurolab management claims that they have significant profit margins. In 2008, Aurolab completed new production facilities in Madurai which will enable a six-fold expansion of production capacity. An unintended consequence of the profitability of the model is that several competing lens manufacturers have been enticed to the Indian market. The positive effect is that Aurolab has incentives to improve manufacturing efficiency to meet competition. For Aravind, competition means more choices on the supply side and further downward pressures on lens manufacturers which is positive for Aravind's overall health service model.

\section{DISCUSSION}

The model we have developed in this paper is only an illustration of the main dimensions of model choices. We have found this technique extremely useful and a solid basis for going into various directions of theorizing (for example see Anonymous, 2010) ${ }^{3}$. Morrison and Morgan (1999: 12) summarize their experience with model-based theorizing by stating that learning comes less from looking at the model and that 'we learn more from building the model and from manipulating it'. Models thus become independent tools for the investigator that mediate between analytical objectives, theory and empirical data. In this paper we followed this conception of models as mediators to specify a systematic and transparent process of modeling the business model of an organization operating in the context of deep poverty. Using the Aravind eye hospital as an illustrative case study, we developed a model that evolved as an outcome of three processes. First, by peeling away elements that do not directly inform our research question, we arrived at a core model specification that provided the content of the model, the elements listed in Figure 3. Second, we generated thought experiments that plausibly configured these elements into the final model that provided us with new explanations and insights addressing our research objective and concrete research question. Third, we strengthened the plausibility of our model by providing evidence for conjectured mechanisms and narratives that provided context and richness beyond the formal model.

Our research interest in Aravind is to understand their opportunities and challenges of scaling organizational impact. Engaging the RBV as the main theoretical lens enabled

\footnotetext{
${ }^{3}$ Authors name withheld to enable anonymous review process.
} 
us to keep the final model simple while being able to represent those aspects of reality that we expected to be informative given our analytical interest. Being conscious of the particular context required an adaptation of the traditional aim of the RBV which is to explain competitive advantage. Competitive advantage is a relative measure but the absence of competition over how to best serve customer needs which defines the context of Aravind requires a different explanandum for which leveraging resources is the explanans. Priem and Butler (2001) see as a shortcoming of the RBV that it does not explain value created for the consumer but uses profitability, i.e., value captured, as its main dependent variable. In the context of deep poverty and the absence of competitive benchmarks we are primarily interested in explaining value creation and perhaps less in value capture as the dominant dependent variable. In addition, we deal with different dimensions or currencies of value, both economic and non-economic, i.e. non-financial. Ray et al., (2004) emphasized the need to disaggregate the dependent variable of firm performance to isolate the effects of how resources and activities create different aspects of value and thus contribute to overall performance. For Aravind this was modeled from the start by specifying four concomitant strategic objectives that have financial, e.g. profits, and non-financial dimensions, e.g. free surgeries. This analytical strategy enabled mapping some of the core mechanisms of value creation, for instance, nurturing a culture that enables high productivity and creates a reputation for quality and fairness or building and managing a network of alliances with resource providers. The model of Aravind makes these links explicit and also links resources and activities to environmental variables that affect performance. In this sense the model constitutes a generative model that accounts for real mechanisms in action as a set of events that collectively explain how outcomes are generated.

The analytical validity of the model is determined by how useful it is to provide answers given our interest in understanding the potential of Aravind's business model to scale. We intend to use the generative model we have developed here as a knowledge container to integrate new insights from Aravind's scaling efforts over time. This is expected to expand but also make our model more robust. For example a partial replication of the Aravind model in Cairo, Egypt, added a free surgery hospital to an existing traditional paying hospital. But overall patient flow increased only slowly, highlighting a number of context-specific differences between India and Egypt. Men and women could not share the same facilities for cultural reasons and this required expensive workarounds. The density of community-based NGOs was much lower in Egypt and the hospital needed to find substitute forms of re-creating this important demand enabler. When the momentum of increasing numbers of free operations finally picked up, the for-profit hospital experienced significant increases in paying patients as well. The new momentum now challenges staff to deal with the inefficiencies of the 
current workflows and to create more value from the limited resources available ${ }^{4}$. This example provides evidence for our proposition that the free surgery part is an essential substructure of our generative model. Inclusion of free surgery in the generative model better explains achievements of other strategic objectives such as productivity as the basis for profits and quality. Adapting this model has allowed us to generate a number of formal propositions about scaling challenges in the same or different context (Anonymous, 2010) ${ }^{5}$. This suggests that our current generative model of Aravind is a useful tool for making informed predictions about context-specific hurdles or enablers of scaling mechanisms and can be adapted to support various research objectives.

\section{Implications for researchers}

Several scholars have pointed out that science progresses along a self-correcting path through variation of conjectures and selective retention of principles that get formalized into models and theories (Radnitzky and Bartley, 1987; Weick, 1989; McKelvey, 2002). Our conceptualization of business models as generative models constitutes common ground that enables progress in several ways. First, it enables integration of new insights to improve the ontological adequacy of the model in relation to the focal organization. This also opens up new avenues for researchers to integrate additional theoretical perspectives to inform different research questions. Second, the concept of a generative model as proposed here creates a transparent language that enables comparative studies across organizations and settings to derive more general theoretical elements. For example, recent work on pro-poor business models indicates interesting properties of alliance structures between companies and social entrepreneurs. The authors highlighted that successful alliances between organizations with different cultures and strategic objectives keep organizational entities strictly separate. Coordination revolves around a transparent exchange of a product or service that provides scale to the business model of one of the partners in exchange for revenues or important resources (Seelos and Mair, 2007). We find the same pattern for the alliance between Aravind and Aurolab managed as separate organizations and exchanging manufactured lenses for payments. Applying consistent modeling approaches thus may enable the building of more general theory by comparing models across organizations (Tsoukas, 1989).

Third, the model informs decision makers in the focal organization to experiment around hypotheses derived from the generative model. The current expansion in scale and scope of the Aravind eye hospital constitutes a number of natural experiments that may enable isolation of new or unearthing hidden mechanisms to expand the generative

\footnotetext{
${ }^{4}$ Information is based on interviews with staff at the Cairo Al-Noor hospital by the author in 2007.

${ }^{5}$ Authors name withheld to enable anonymous review process.
} 
model. This is in line with the proposed opportunity for more engaged scholarship (Van de Ven, 2007). Finally, models enable a potentially collaborative approach between the disconnected empirical researchers and those who seek theoretical synthesis. Franck sees this divorce as a "deep malaise in the social sciences". He sees modeling and scientific models as an important way of bridging this gap (Franck, 2002). An important element of model validity lies in its usefulness for researchers to independently work on the analytical and the ontological aspects. The model coordinates and integrates inputs from both sides. Walsh et al. (2005) also emphasized the need to learn from mistakes and not just success stories. Models thus serve as platforms that enable communication and cooperative work across scientists with different commitments towards the target system (Godfrey-Smith, 2006). This gives rise to a model-based self-correcting evolutionary epistemology that facilitates stepwise progress towards better theories (Azevedo, 1979; McKelvey, 2002).

\section{Implications for practitioners}

The practical relevance of academic research and management education at business schools has been questioned for some time. Scholars point to a disturbing gap between theory and practice (Baldridge, Floyd and Markoczy, 2004; Bennis and O'Toole, 2004; Van de Ven and Johnson, 2006). We regularly use generative models in research, education and for consulting with organizations in both for-profit and not-for-profit sectors. We have found the process of modeling to be a fruitful platform for individuals or groups to clarify assumptions and meanings of concepts and to make the links between theory and reality explicit. This is a collaborative learning opportunity that imposes the requirement of thoroughly understanding selected academic literature and how it links to the observable world. For many organizations the model is also a useful tool to communicate their business model to internal and external stakeholders, thus facilitating better internal coordination of activities and external evaluation of an organization's potential. For organizations in the not-for-profit sector this might facilitate interaction with philanthropists to highlight the most productive uses of donations, for example, to identify and eliminate important bottlenecks in a business model to achieve scale.

One useful application is to think about new innovative business models at the BoP. Companies may be able to leverage important resources and competencies that social enterprises have created often over long-time periods. Understanding the business models of social enterprises is required in order to find points that enable companies to dock on to the business models of social enterprises. Aravind management revealed that discussions with the leading lens manufacturer in the early 1990s were not fruitful over concerns that India is not a viable market. While Aurolab is a non-profit structure, we speculate that an existing lens-manufacturing company might have been able to combine its capital and technical resources and manufacturing capabilities with 
Aravind's brand and its capabilities in order to orchestrate large scale and high productivity eye surgery. Aravind might have agreed to the need for a corporate partner to capture some of the value created for its shareholders given the extent of overall social value created by this model. As David Green from Aurolab, Aravind's lense manufacturing company, said in a recent speech addressing MBA students: 'I am waiting for companies to compete with me or put me out of business for the benefit of the poor'.

\section{CONCLUSIONS}

The term business model is used abundantly in the managerial sciences as a concept that relates to a variety of scholarly and practitioner interests and perspectives. In this paper we focus on the benefits that the term model in business model potentially holds for social science practice. Model building is portrayed as both a creative and analytically rigorous and transparent process that can be employed for a variety of research objectives as well as practitioner interests. Modeling is fun! Modeling is also intellectually penetrating and moves researchers out of the comfort zone of staying within the theory or statistical analysis. Modeling requires deep reflection on the meanings of concepts and how they relate or correspond to the real world. It requires an explicit stance by the researcher on her ontological and epistemological commitments. Modeling also satisfies the expectation that good social science is useful in making a contribution to social progress as was the expectation on the liberation of reason-based sciences during the Enlightenment. The formality involved in model building as outlined here also supports the conclusion that good models are useful models but not necessarily vice versa! 


\section{REFERENCES}

Applegate LM. 2001. E-business models: making sense of the internet business landscape. In Information Technology and the Future Enterprise: New Models for Managers, Dickson G, Gary W, DeSanctis G (eds). Prentice Hall: Upper Saddle River.

Azevedo J. 1997. Mapping Reality: An Evolutionary Realist Methodology for the Natural and Social Sciences. University of New York Press: Albany.

Baldridge DC, Floyd SW, Markoczy L. 2004. Are managers from mars and academicians from venus? toward an understanding of the relationship between academic quality and practical relevance. Strategic Management Journal, 25: 10631074.

Barney J, Wright M, Ketchen Jr. DJ. 2001. The resource-based view of the firm: ten years after 1991. Journal of Management 27: 625-641.

Bennis WG, O'Toole J. 2004. How business schools lost their way. Harvard Business Review 83(5): 96-104.

Bhaskar R. 1978. A Realist Theory of Science. Harvester Press: Hassocks, England.

Boumans M. 1999. Built-in justification. In Models as Mediators: Perspectives on Natural and Social Science, Morgan MS, Morrison M (eds). Cambridge University Press: Cambridge; 66-96.

Bourgeois III LJ. 1979. Toward a method of middle-range theorizing. Academy of Management Review 4(3): 443-447.

Brante T. 2010. Review essay: perspectival realism, representational models, and the social sciences. Philosophy of the Social Sciences 40(1): 107-117.

Brilliant L, Brilliant G. 2007. Aravind: partner and social science innovator (innovations case discussion: Aravind eye care system). Innovations: Technology, Governance, Globalization 2: 50-52.

Bunge M. 1997. Mechanisms and explanation. Philosophy of the Social Sciences 27(4): 410-465.

Bunge M. 2004. How does it work?: the search for explanatory mechanisms. Philosophy of the Social Sciences 34(2): 182-210.

Bunge M. 2006. Chasing Reality: Strife over Realism. University of Toronto Press: Toronto.

Campbell DT. 1987. Evolutionary epistemology. In Evolutionary epistemology, rationality, and the sociology of knowledge, Radnitzky G, Bartley III WW (eds). Open Court Publishing Co: La Salle; 47-90. 
Certo ST, Miller T. 2008. Social entrepreneurship: key issues and concepts. Business Horizons 51: 267-271.

Chesbrough H. 2007. Business model innovation: it's not just about technology anymore. Strategy \& Leadership 35: 12-17.

Chesbrough HW, Rosenbloom, RS. 2002. The role of the business model in capturing value from innovation: evidence from Xerox corporation's technology spin-off companies. Industrial and Corporate Change 11: 529-556.

Chesbrough H, Ahern S, Finn M, Guerraz S. 2006. Business models for technology in the developing world: the role of non-governmental organizations. California Management Review 48: 48-61.

Demetriou C. 2009. The realist approach to explanatory mechanisms in social science. More than a heuristic? Philosophy of the Social Sciences 39(3): 440-462.

Downes S. 1992. The importance of models in theorizing: a deflationary semantic view. In Philosophy of Science Association (vol. 1), Hull D, Forbes M, Okruhlik K (eds). East Lansing; 142-153.

Frigg R, Hartmann S. 2009. Models in science. In Stanford Encyclopedia of Philosophy (Summer 2009 Edition), Zalta EN, (ed.), URL = <http://plato.stanford.edu/archives/sum2009/entries/models-science/>.

Franck R. 2002. General Introduction. In The Explanatory Power of Models. Bridging the Gap Between Empirical and Theoretical Research in The Social Sciences, Franck R, (ed.). Kluwer: The Netherlands; 1-8.

Ghaziani A, Ventresca MJ. 2005. Keywords and cultural change: frame analysis of business model public talk, 1975-2000. Sociological Forum 20: 523-559.

Giere RN 1999. Science Without Laws. University of Chicago Press: Chicago.

Giere RN 2006. Scientific Perspectivism. University of Chicago Press: Chicago.

Godfrey-Smith P. 2006. The strategy of model-based science. Biology and Philosophy 21: $725-740$.

Hart S. 2007. Capitalism at the Crossroads: The Unlimited Business Opportunities in Solving the World's Most Difficult Problems. Wharton School Publishing: Upper Saddle River.

Hartmann S. 2008. Modeling in philosophy of science. In Representation, Evidence, and Justification: Themes from Suppes, Frauchiger M, Essler, WK (eds). Ontos: Frankfurt.

Hedman J, Kalling T. 2003. The business model concept: theoretical underpinnings and empirical illustrations. European Journal of Information Systems, 12: 49-59. 
Jaiswal AK. 2008. The fortune at the bottom or the middle of the pyramid? Innovations: Technology, Governance, Globalization 3: 85-100.

Johnson P, Duberley J. 2000. Understanding Management Research: An Introduction to Epistemology. Sage: London.

Karnani A. 2007. The mirage of marketing to the bottom of the pyramid: how the private sector can help alleviate poverty. California Management Review 49: 90-111.

Khanna T, Palepu K. 1997. Why focused strategies may be wrong for emerging markets. Harvard Business Review 75(4): 41-51.

Lockett A, O'Shea RP, Wright M. 2008. The Development of the resource-based view: reflections from Birger Wernerfelt. Organization Studies 29: 1125-1141.

Magretta J. 2002. Why business models matter. Harvard Business Review 80(5): 86-92.

Mahadevan B. 2000. Business Models for internet-based e-commerce. California Management Review 42: 55-69.

Mahoney J. 2001. Review: Beyond Correlational Analysis: Recent Innovations in Theory and Method. Sociological Forum 16(3): 575-593.

Mäki U. 2010. Models and truth. The functional decomposition approach. In EPSA Epistemology and Methodology of Science: Launch of the European Philosophy of Science Association, Suarez M, Dorato M, Redei M (eds). Springer: New York; 177-187.

McKelvey B. 2000. Toward a model-centered strategy of science: more experiments, less history. In Research in Competence-Based Management, Sanchez R, Heene A (eds). JAI Press: Stamford CT; 217-253.

McKelvey B. 2002. Model-centered organization science epistemology. In The Blackwell Companion to Organizations. Baum JAC (ed). Blackwell: Oxford; 752-780.

Merton RK. 1968. Social Theory and Social Structure (enlarged ed.). Free Press: New York.

Morgan MS, Morrison M. (eds.). 1999. Models as Mediators: Perspectives on Natural and Social Science. Cambridge: Cambridge University Press.

Morrison M, Morgan MS. 1999. Models as mediating instruments. In Models as Mediators: Perspectives on Natural and Social Science, Morgan MS, Morrison M (eds). Cambridge University Press: Cambridge; 10-37.

North DC. 1994. Economic performance through time. American Economic Review 84(3): 359-368.

Pawson R. 1989. A Measure for Measures: A Manifesto for Empirical Sociology. Routledge: London. 
Peirce CS. 1982. Writings of Charles S. Peirce: A Chronological Edition. 6 vols. Moore EC. et al. (eds). Indiana University Press: Bloomington.

Penrose RD. 1959. The Theory of the Growth of the Firm. John Wiley and Sons: New York.

Pickel A. 2007. Rethinking systems theory: a programmatic introduction. Philosophy of the Social Sciences 37(4):391-407.

Porter ME. 2001. Strategy and the internet. Harvard Business Review 79(3): 62-78.

Prahalad CK. 2005. The Fortune at the Bottom of the Pyramid. Wharton School Publishing: Upper Saddle River.

Priem RL, Butler JE. 2001. Is the resource-based "view" a useful perspective for strategic management research? Academy of Management Review 26: 22-40.

Radnitzky G, Bartley III, W. W. (eds). 1987. Evolutionary Epistemology, Rationality, and the Sociology of Knowledge. Open Court Publishing Co: La Salle.

Rangan VK, Thulasiraj RD. 2007. Making sight affordable (innovations case narrative: the Aravind eye care system). Innovations: Technology, Governance, Globalization 2: 35-49.

Ray G, Barney JB, Muhanna W. 2004. Capabilities, business processes, and competitive advantage, choosing the dependent variable in empirical tests of the resource-based view. Strategic Management Journal 25: 23-37.

Reed M. 2005. Reflections on the realist turn in organisation and management studies. Journal of Management Studies 42: 1621-1644.

Rubin PH. 1973. The expansion of firms. Journal of Political Economy 84: 936-949.

Sawyer RK. 2004.The Mechanisms of Emergence. Philosophy of the Social Sciences 34(2): 260-282.

Sayer A. 1992. Methods in Social Science. A Realist Approach. Routledge: New York.

Schweizer L. 2005. Concept and evolution of business models. Journal of General Management 31: 37-56.

Shafer SM, Smith HJ, Linder JC. 2005. The power of business models. Business Horizons 48: 199-207.

Seelos C, Mair J. 2005. Social entrepreneurship: creating new business models to serve the poor. Business Horizons 48: 241-246.

Seelos C, Mair J. 2007. Profitable business models and market creation in the context of deep poverty: A Strategic View. Academy of Management Perspectives 21: 49-63. 
Short JC, Moss TW, Lumpkin GT. 2009. Research in social entrepreneurship: past contributions and future opportunities. Strategic Entrepreneurship Journal 3(2): 161-194.

Sirmon D, Hitt MA, Ireland RD. 2007. Managing firm resources in dynamic environments to create value: looking inside the black box. Academy of Management Review 32: 273292.

Suarez M, Cartwright N. 2008. Theories: tools vs. models. Studies in the History and Philosophy of Modern Physics 39: 62-81.

Suppe F. 2000. Understanding Scientific Theories: An Assessment of Developments, 1969-1998. Philosophy of Science 67, Supplement. Proceedings of the 1998 Biennial Meetings of the Philosophy of Science Association. Part II: Symposia Papers: S102S115.

Suppe F. 1989. The Semantic Conception of Theories and Scientific Realism. University of Illinois Press: Chicago.

Suppes P. 1962. Models of Data, In Logic, Methodology and Philosophy of Science: Proceedings of the 1960 International Congress, Nagel E, Suppes P, Tarski A (eds). Stanford University Press: Stanford; 251-261.

Suppes P. 2002. Representation and Invariance of Scientific Structures. CSLI Publications: Stanford.

Tabin G. 2007. The cataract blindness challenge (innovations case discussion: Aravind eye care system). Innovations: Technology, Governance, Globalization 2: 53-57.

Tsoukas H. 1989. The validity of idiographic research explanations. Academy of Management Review 14: 551-561.

Van De Ven AH, Johnson PE. 2006. Knowledge for theory and practice. Academy of Management Review 31: 802-821.

Van De Ven AH. 2007. Engaged Scholarship: A Guide for Organizational and Social Research. Oxford University Press: New York.

Van Fraassen BC. 1980. The Scientific Image. Oxford University Press: Oxford.

Walsh JP, Kress JC, Beyerchen KW. 2005. Book review essay: promises and perils at the bottom of the pyramid. Administrative Science Quarterly 50: 473-482.

Weick KE. 1989. Theory construction as disciplined imagination. Academy of Management Review 14: 516-531.

World Health Organization. 1997. WHO Fact Sheet N230.

World Health Organization. 1999. WHO Fact Sheet N143. 